\title{
Urchin-like NiO Superstructures Prepared by Simple Thermal Decomposition Process
}

Hua Jiao

(Received 23 June 2011; accepted 20 August 2011; published online 5 September 2011.)

\begin{abstract}
Urchin-like $\mathrm{NiO}$ superstructures have been prepared via a thermal decomposition reaction of $\mathrm{NiC}_{2} \mathrm{O}_{4}$ at $400^{\circ} \mathrm{C}$ for $1 \mathrm{~h}$. The morphology and structure of the synthesized urchin-like superstructures have been characterized by X-ray diffraction, field emission scanning electron microscopy and transmission electron microscopy. The results show that urchin-like NiO superstructures were a polycrystal with cubic structure and typical diameters of 200 to $500 \mathrm{~nm}$ and the self-assembly nanoparticles average diameter is $14 \mathrm{~nm}$. The as-prepared $\mathrm{NiO}$ superstructures have a high Brunauer-Emmett-Teller surface area of about $60.32 \mathrm{~m}^{2} / \mathrm{g}$. The UV-vis spectrum of urchin-like $\mathrm{NiO}$ consists of one peak at $357 \mathrm{~nm}(3.47 \mathrm{eV})$.
\end{abstract}

Keywords: NiO superstructures; Thermal decomposition; Ultraviolet analysis

Citation: Hua Jiao, "Urchin-like NiO Superstructures Prepared by Simple Thermal Decomposition Process", Nano-Micro Lett. 3 (3), 166-170 (2011). http://dx.doi.org/10.3786/nml.v3i3.p166-170

\section{Introduction}

As a p-type wide-bandgap semiconductor, $\mathrm{NiO}$ is a very promising functional material which has attracted increasing attention due to its extensive important applications such as battery electrodes [1], catalysts [2], and gas sensors [3-5]. To date, many NiO nanostructures have been prepared, such as nanoplates [6], nanorings [7], nanobelts [8], nanowires [9], nanotubes [10], mesoporous $\mathrm{NiO}$ [11], hollow octahedral [12], polyhedrons [13] and $\mathrm{NiO}$ hollow nanospheres [14-17]. The previous works, NiO 3D superstructures (hollow tubes or spheres) often were prepared by template assistant. Therefore, developing simple, high-yield, and environmentally benign methods for synthesizing $\mathrm{NiO}$ complex $3 \mathrm{D}$ superstructures is still an on-going process. However, to the best of our knowledge, few reports have been concerned the synthesis of $\mathrm{NiO}$ nanocrystals as nanoscale building blocks for the construction of urchinlike 3D superstructures.

Herein, urchin-like NiO 3D superstructures were prepared via a simple thermal decomposition method without any template or free surfactant. Urchin-like NiO su- perstructures were assembled from nanocrystals building blocks.

\section{Experimental}

\section{Experimental materials}

All the chemical reagents in the experiments were analytical grade (AR) and they were used without further purification. Nickel sulfate $\left(\mathrm{NiSO}_{4} \cdot 7 \mathrm{H}_{2} \mathrm{O}\right.$, AR, Tianjin Zhiyuan Chemical Reagent Co., Ltd), oxalic acid $\left(\mathrm{C}_{2} \mathrm{H}_{2} \mathrm{O}_{4} \cdot 2 \mathrm{H}_{2} \mathrm{O}, \mathrm{AR}, \mathrm{Xi}\right.$ 'an Reagent Factory).

\section{Syntheses of urchin-like $\mathrm{NiO}$ superstructures}

In the typical experiment, $2.84 \mathrm{~g}$ of $\mathrm{NiSO}_{4} \cdot 7 \mathrm{H}_{2} \mathrm{O}$ $(0.01 \mathrm{~mol})$ was dissolved into $30 \mathrm{ml}$ ethylene glycol with continuously stirring about $90 \mathrm{~min}$. Then, $20 \mathrm{ml}$ $0.5 \mathrm{~mol} / \mathrm{l}$ of $\mathrm{H}_{2} \mathrm{C}_{2} \mathrm{O}_{4}(0.02 \mathrm{~mol})$ were added into the solution to form light green precipitate. The precipitate was collected by centrifugation and washed with deionized water and absolute ethanol for several times. After that the precipitate was placed in oven and maintained at $400^{\circ} \mathrm{C}$ for $1 \mathrm{~h}$ with a heating rate of $10^{\circ} \mathrm{C} / \mathrm{min}$ before

College of chemistry and science, Weinan Teachers University, Weinan, 714000, China

Corresponding author. E-mail: jiaohua0106@yahoo.com.cn 
being naturally cooled to room temperature.

\section{Characterization of Products}

X-ray powder diffraction (XRD) patterns of the products were obtained on a Japan Rigaku D/Max-IIIC diffractometer at a voltage of $60 \mathrm{kV}$ and a current of $80 \mathrm{~mA}$ with $\mathrm{Cu} \mathrm{K} \alpha$ radiation $(\lambda=1.5406 \AA)$, employing a scanning rate of $8^{\circ} / \mathrm{min}$ in the $2 \theta$ ranging from $20^{\circ}$ to $80^{\circ}$. Field emission scanning electron microscopy (FESEM) images were explored on a JEOL JSM-6700F microscope. Transmission electron microscopy (TEM) images were taken on a JEOL JEM-3010 transmission electron microscope at an accelerating voltage of $200 \mathrm{kV}$. Thermogravimetry (TG) and Differential thermal analysis (DTA) measurements were simultaneously measured up to $500^{\circ} \mathrm{C}$ at a heating rate of $10^{\circ} \mathrm{C} / \mathrm{min}$ using a Shanghai ZRY-2P. UV-vis absorption spectrum was taken on a UV, Lambda 950 spectrophotometer. $\mathrm{N}_{2}$ adsorption was determined by BET measurements using a Beijing JW-BK surface area analyzer.

\section{Results and Discussion}

\section{TG/DTA}

In order to study the thermal decomposition characteristics of nickel oxalate precursor, the thermogravimetry-differential thermal analysis (TGDTA) curves of the as-prepared precursor were shown in Fig. 1. The TG curve showed that a major step weight loss was about $48.73 \%$, closed to the theoretical value $(48.98 \%)$, which was corresponded to the decomposition of the precursor started at about 360 . It is indicated that the decomposition temperature of the precursor was at about $360^{\circ} \mathrm{C}$. Moreover, when the temperature was above $360^{\circ} \mathrm{C}$, TG/DTA curves were maintained on a level, indicating that the precursor decomposed completely. In addition, the results were also used to determine the temperature of the thermal treatment of the precursors. Finally, $400^{\circ} \mathrm{C}$ was selected as the decomposition temperature.

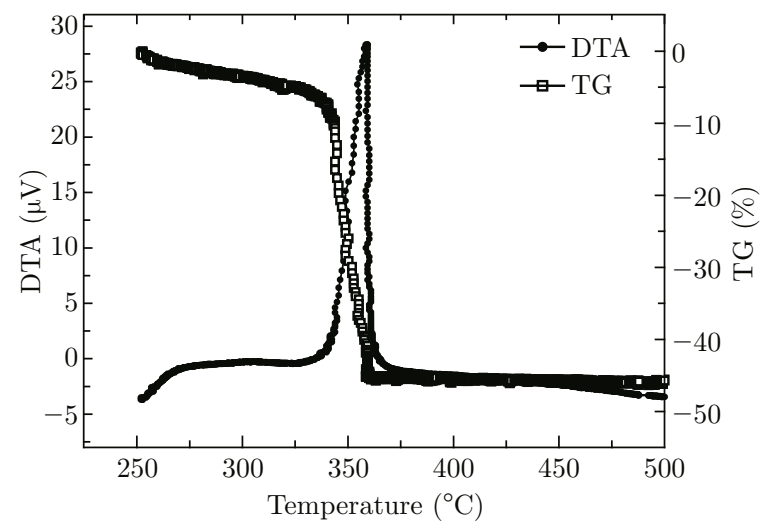

Fig. 1 TG/DTA curve of the obtained $\mathrm{NiO}$ precursor.
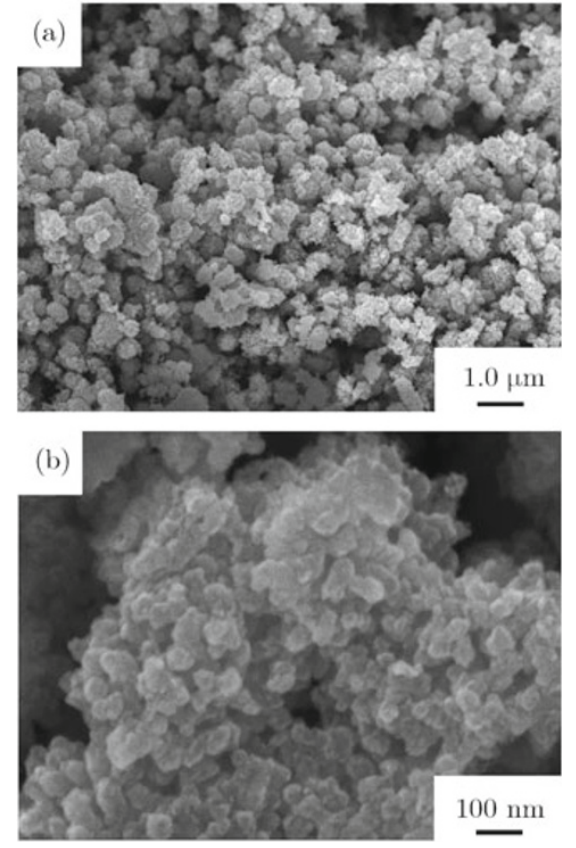

Fig. 2 FESEM image of samples obtained at $400^{\circ} \mathrm{C}$ for $1 \mathrm{~h}$.

\section{FESEM}

Typical FESEM images of the $\mathrm{NiO}$ were shown in Fig. 2. Figure 2(a) is an overview of the samples with the uniform urchin-like superstructures with a length from 200 to $500 \mathrm{~nm}$. A high multiple FESEM image is shown in Fig. 2(b). The urchin-like NiO superstructures might derive from a mount of nanocrystals by self-assembly under Vander Waals forces. Meanwhile, several particles together formed soft agglomerates.

\section{XRD}

XRD pattern of $\mathrm{NiO}$ sample obtained at $400^{\circ} \mathrm{C}$ for $1 \mathrm{~h}$ is shown in Fig. 3, which agreed well with the reported data (JCPDS No. 47-1049). NiO possessed a cubic structure and the average grain size of the $\mathrm{NiO}$ nanocrystals self-assembling superstructures was $14 \mathrm{~nm}$ calculated from Scherrer's equation. No other peaks for the impurities were observed.

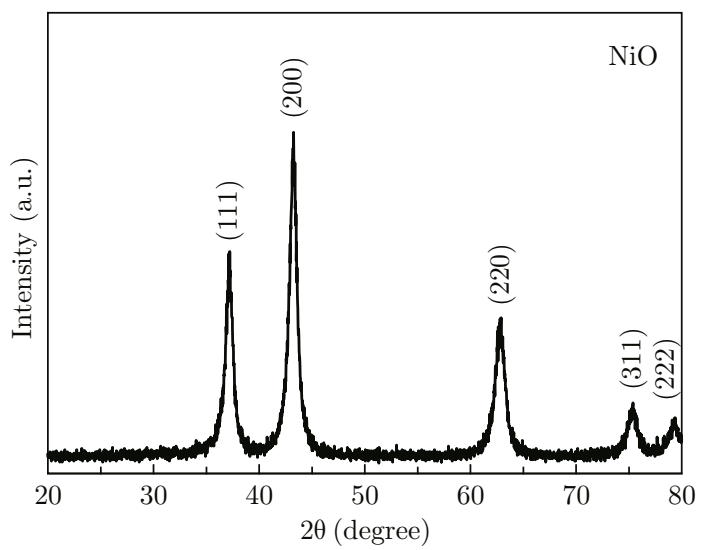

Fig. $3 \mathrm{XRD}$ image of samples obtained at $400^{\circ} \mathrm{C}$ for $1 \mathrm{~h}$. 

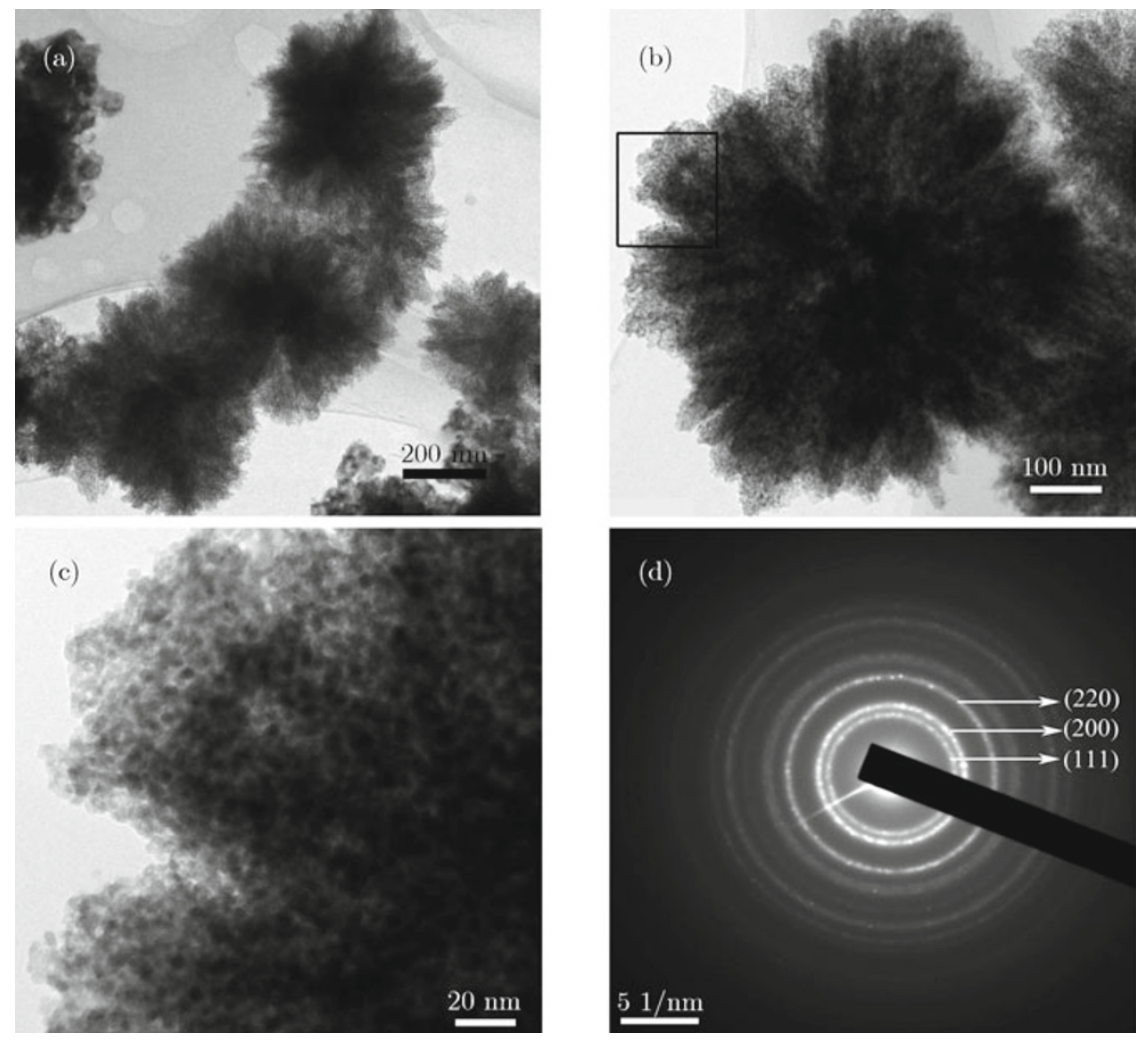

Fig. 4 TEM and SAED images of samples obtained at $400^{\circ} \mathrm{C}$ for $1 \mathrm{~h}$. (a c) TEM; (d) SAED.

\section{TEM}

Further characterization of the $\mathrm{NiO}$ superstructures was performed by TEM and selected area electron diffraction (SEAD), as shown in Fig. 4. Figure 4(a) showed amount of the as-prepared urchin-like $\mathrm{NiO}$ superstructures. The average size of superstructures was about $400 \mathrm{~nm}$. A typical TEM image of single urchinlike $\mathrm{NiO}$ superstructures was shown in Fig. 4(b) with the size of $400 \mathrm{~nm}$. The superstructures assembled from the nanocrystals can be observed in the high multiple TEM image (see Fig. 4(c)), which is according to rectangular frame of Fig. 4(b). Meanwhile, SAED pattern is presented in Fig. 4(d) according to Fig. 4(c), indicated the polycrystalline cubic phase of $\mathrm{NiO}$ (111), (200), (220) crystal plane diffraction. The TEM and SAED analyses revealed that urchin-like $\mathrm{NiO}$ superstructures were polycrystalline cubic structure.

\section{$\mathrm{UV} /$ vis absorption spectra}

The UV/vis absorption spectra of the as-synthesized urchin-like $\mathrm{NiO}$ superstructures were illustrated in Fig. 5. It can be seen that the morphological changes of the $\mathrm{NiO}$ semiconductor were accompanied by remarkable changes in the UV-vis spectra because of the significant difference in crystal size associated with $\mathrm{NiO}$ [18]. In this case, a peak of $357 \mathrm{~nm}$ was observed with the $\mathrm{NiO}$ average grain size of $14 \mathrm{~nm}$ composing the su- perstructures. The bandgap energy of urchin-like $\mathrm{NiO}$ superstructures is about $3.47 \mathrm{eV}$, which is smaller than the value $(3.55 \mathrm{eV})$ reported by $\mathrm{Yu}$ Lin et al. [19], and also smaller than the normal $\mathrm{NiO}$ value $(3.6 \sim 4.0 \mathrm{eV})$. The optical band edge exhibited obvious red shift.

\section{BET isotherm of urchin-like $\mathrm{NiO}$ superstruc- tures}

As the product expected to have a high surface area, Brunauer-Emmett-Teller (BET) measurements were performed. The surface area of the urchin-like $\mathrm{NiO}$ superstructures obtained at $400^{\circ} \mathrm{C}$ calculated from the BET plot was $60.32 \mathrm{~m}^{2} / \mathrm{g}$ (Fig. 6), which was lower than that ordered mesoporous $\mathrm{NiO}\left(81.8 \mathrm{~m}^{2} / \mathrm{g}\right)[20], \mathrm{NiO}$

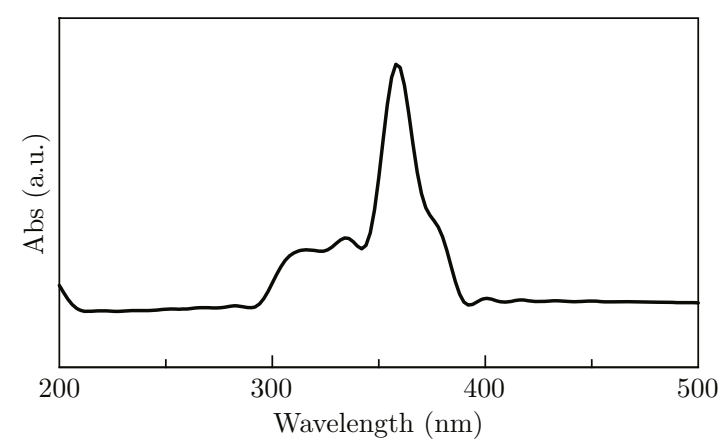

Fig. $5 \mathrm{UV} /$ vis absorption spectra of urchin-like $\mathrm{NiO}$ superstructures. 


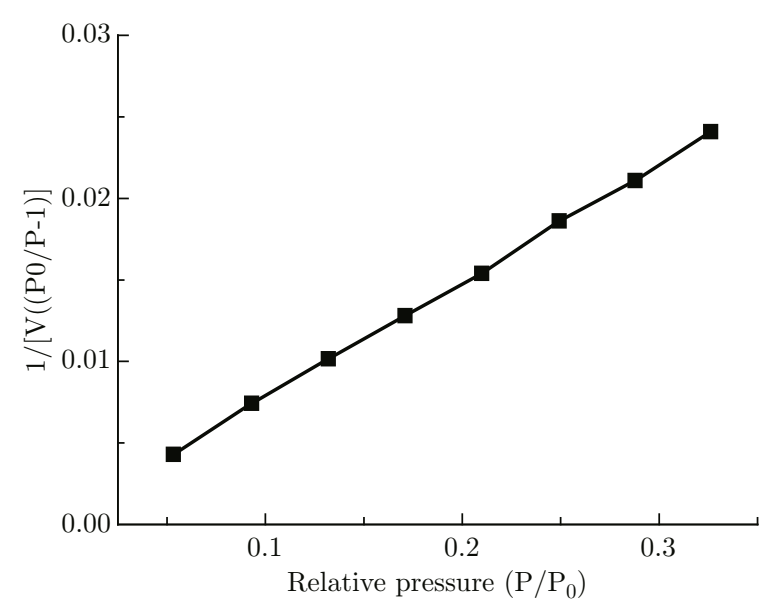

Fig. 6 the plot of BET isotherm for $\mathrm{N}_{2}$ adsorptiondesorption.

microspheres $\left(81 \mathrm{~m}^{2} / \mathrm{g}\right)$ and higher than that $\mathrm{NiO}$ nanorods $\left(13 \mathrm{~m}^{2} / \mathrm{g}\right)$ [18]. This result suggests that each of urchin-like $\mathrm{NiO}$ structure grows from the cores of the urchin-like $\mathrm{NiO}$ superstructures.

\section{The reaction mechanism}

In this work, a facile route, namely direct thermal decomposition reaction of $\mathrm{NiC}_{2} \mathrm{O}_{4}$ in an oven, has been developed to synthesize novel 3D urchin-like $\mathrm{NiO}$ superstructures. The chemical reaction for syntheses of $3 \mathrm{D}$ urchin-like $\mathrm{NiO}$ superstructures can be expressed as:

$$
\begin{gathered}
\mathrm{NiSO}_{4} \cdot 7 \mathrm{H}_{2} \mathrm{O} \stackrel{\mathrm{C}_{2} \mathrm{H}_{6} \mathrm{O}_{2}}{\longrightarrow} \mathrm{Ni}^{2+}+\mathrm{SO}_{4}^{2-}+7 \mathrm{H}_{2} \mathrm{O} \\
\mathrm{C}_{2} \mathrm{H}_{2} \mathrm{O}_{4} \cdot 2 \mathrm{H}_{2} \mathrm{O}+\mathrm{Ni}^{2+}+\mathrm{SO}_{4}^{2-} \stackrel{\mathrm{C}_{2} \mathrm{H}_{6} \mathrm{O}_{2}}{\longrightarrow} \\
\mathrm{NiC}_{2} \mathrm{O}_{4} \downarrow+2 \mathrm{H}^{+}+\mathrm{SO}_{4}^{2-}+2 \mathrm{H}_{2} \mathrm{O} \\
\mathrm{NiC}_{2} \mathrm{O}_{4} \stackrel{\triangle}{\longrightarrow} \mathrm{NiO} \downarrow+\mathrm{CO} \uparrow+\mathrm{CO}_{2} \uparrow
\end{gathered}
$$

At the beginning, the $\mathrm{C}_{2} \mathrm{O}_{4}^{2-}$ was added into $\mathrm{Ni}^{2+}$ ethylene glycol solution and $\mathrm{NiC}_{2} \mathrm{O}_{4}$ precipitation formed (see Eq. $(1 \sim 2)$ ). Second, NiO superstructures can be obtained as the decomposition reaction of $\mathrm{NiC}_{2} \mathrm{O}_{4}$ precipitation occurred (see Eq. (3)).

\section{Conclusions}

In summary, the work presented here constitutes a simple thermal decomposition method for the fabrication of urchin-like $\mathrm{NiO}$ superstructures. The simplicity is that the aging procedure results in the growth of $\mathrm{NiO}$ nanocrystals as well as their assembly into urchin-like structures. It has been found that synthesis of precursor was a key to obtain urchin-like morphology. The urchin-like $\mathrm{NiO}$ superstructures would open up the possibility of finding their new applications or improving existing performance, for example, as candidates for studying the nanoarchitecture-dependent performance as cathodes in micro-rechargeable lithium batteries. To this purpose, the structures of urchin-like $\mathrm{NiO}$ are to be investigated in more detail, as well as on the effect of incorporation of functional additives into the shells.

\section{Acknowledgment}

This work was supported by Fund of Weinan Teachers University (10YKF014).

\section{References}

[1] B. Varghese, M. V. Reddy, Y. W. Zhu, S. L. Chang, T. C. Hoong, G. V. Subba Rao, B. V. R. Chowdari, T.S. W. Andrew, T. L. Chwee and H. S. Chorng, Chem. Mater. 20, 3360(2008). http://dx.doi.org/10.1021/ $\mathrm{cm} 703512 \mathrm{k}$

[2] T. Y. Kim, J. Y. Kim, S. H. Lee, H. W. Shim, S. H. Lee, E. K. Suh and K. S. Nahm, Synth. Met. 144, 61(2004). http://dx.doi.org/10.1016/j.synthmet. 2004.01 .010

[3] J. A. Dirksen, K. Duval and T. A. Ring, Sens. Actuators B-Chem. 80, 106(2001). http://dx.doi.org/10. 1016/S0925-4005(01) 00898-X

[4] I. Hotovy, V. Rehacek, P. Siciliano, S. Capone and L. Spiess, Thin Sol. Films 418, 9(2002). http://dx.doi. org/10.1016/S0040-6090(02)00579-5

[5] M. Matsumiya, F. Qiu, W. Shin, N. Izu, N. Murayama and S. Kanzaki, Thin Sol. Films 419, 213(2002). http://dx.doi.org/10.1016/ S0040-6090(02) 00762-9

[6] X. Wang, L. Li, Y. G. Zhang, S. T. Wang, Z. D. Zhang, L. F. Fei and Y. T. Qian, Cryst. Growth Des. 6, 2163(2006). http://dx.doi.org/10.1021/cg060156w

[7] X. H. Liu, G. Z. Qiu, Z. Wang and X. G. Li, Nanotechnology 16, 1400(2005). http://dx.doi.org/10.1088/ 0957-4484/16/8/071

[8] X. M. Ni, Q. B. Zhao, F. Zhou, H. G. Zheng, J. Cheng and B. B. Li, J. Cryst. Growth. 289, 299(2006). http://dx.doi.org/10. 1016/j.jcrysgro.2005.10.017

[9] Z. Y. Wu, C. M. Liu, L. Guo, R. Hu, M. I. Abbas, T. D.Hu and H. B. Xu, J. Phys. Chem. B109, 2512(2005). http://dx.doi.org/10.1021/jp0466183

[10] S. A. Needham, G. X. Wang and H. K. Liu, J. Power Sources. 159, 254(2006). http://dx.doi.org/ 10.1016/j.jpowsour. 2006.04.025

[11] F. Jiao, A. H. Hill, A. Harrison, A. Berko, A. V. Chadwick and P. G. Bruce, J. Am. Chem. Soc. 130, 5262(2008). http://dx.doi.org/10.1021/ja710849r

[12] X. Wang, L. J. Yu, P. Hu and F. L. Yuan, Cryst. Growth Des. 7, 2415(2007). http://dx.doi.org/10. 1021/cg060957z

[13] Z. Wei, M. Yao, L. Guo, Y. M. Li, J. H. Li and S. H. Yang, J. Am. Chem. Soc. 131, 2959(2009). http://dx. doi.org/10.1021/ja808784s 
[14] D. B. Wang, C. X. Song, Z. S. Hu and X. J. Fu, Phys. Chem. B. 109, 1125(2005). http://dx.doi.org/10. 1021/jp046797o

[15] X. M. Sun, J. F. Liu and Y. D. Li, Chem. Eur. J. 12, 2039(2006). http://dx.doi.org/10.1002/chem. 200500660

[16] J. Liu, S. F. Du, L. Q. Wei, H. D. Liu, Y. J. Tian and Y. F. Chen, Mater. Lett. 60, 3601(2006). http://dx. doi.org/10.1016/j.matlet.2006.03.068
[17] Y. Wang, Q. S. Zhu and H. G. Zhang, Chem. Commun. 5231(2005). http://dx.doi.org/10.1039/b508807km

[18] X. F.Song, L. Gao, J. Phys. Chem. C 112, 15299(2008). http://dx.doi.org/10.1021/jp804921g

[19] Y. Lin, T. Xie, B. Cheng, B. Y. Geng and L. D. Zhang, Chem. Phys. Lett. 380, 521(2003). http://dx.doi.org/10.1016/j.cplett.2003.09.066

[20] J. Feng, H. H. Adrian, H. Andrew, B. Aaron, V. C. Alan and G. B. Peter, J. Am. Chem. Soc. 130, 5262(2008). http://dx.doi.org/10.1021/ja710849r 